International Research Journal of Management, IT \& Social Sciences
Available online at https://sloap.org/journals/index.php/irjmis/
Vol. 6 No. 6, November 2019, pages: 17 28
ISSN: 2395-7492
https://doi.org/10.21744/irjmis.v6n6.741

\title{
Geographic Information System for Manabí Sustainable Development
}

\author{
José Javier Bravo Bazurto ${ }^{\text {a }}$ \\ Victor Alfonso Martínez Falcones ${ }^{\text {b }}$ \\ María Rodríguez Gámez ${ }^{\mathrm{c}}$ \\ María Giuseppina Vanga Arvelo ${ }^{\mathrm{d}}$
}

Article history:

Received: 18 May 2019

Accepted: 31 July 2019

Published: 10 September 2019

\section{Keywords:}

GeoWeb; sustainability;

renewable sources of energy; geographic information system; information technology;

\begin{abstract}
One of the barriers that are recognized based on the sustainable development of the territories is related to the lack of information. This research aims to design a Geographic Information System for information management of Renewable Energy Sources (FRE), which improve its quality, energy efficiency and enhance the diversification of generation sources in the province of Manabí, Ecuador. Following a documentary and applied research, the proposed system will be shown through a GeoWeb where it is intended to replace the manual way of updating information regarding FRE, conventional energy sources and renewable potentials by an automated system, with greater consistency and facilitating the handling and access to information quickly and safely; In addition to making viable the decision-making and the conception of strategies, with an integrating vision that allows to move from the current energy model that is based on fossil fuels to an energy-sustainable one.
\end{abstract}

2395-7492@ Copyright 2019. The Author. This is an open-access article under the CC BY-SA license (https://creativecommons.org/licenses/by-sa/4.0/) All rights reserved.

\section{Author correspondence:}

José Javier Bravo Bazurto,

Information Technology and Communications Department.

Universidad Técnica de Manabí. Portoviejo, Ecuador.

Email address:jbravo@utm.edu.ec

\section{Introduction}

The need to have energy-sustainable and safe territories in the face of any threat of natural disasters implies that higher education centers play a dynamic role in the claims of territorial development. In this context, the Technical University of Manabí (UTM) in Ecuador, must face challenges where students, professors, and researchers can direct

\footnotetext{
${ }^{a}$ Universidad Técnica de Manabí, Portoviejo, Ecuador

${ }^{\mathrm{b}}$ Universidad Técnica de Manabí, Portoviejo, Ecuador

${ }^{\text {c } U n i v e r s i d a d ~ T e ́ c n i c a ~ d e ~ M a n a b i ́, ~ P o r t o v i e j o, ~ E c u a d o r ~}$

${ }^{\mathrm{d}}$ Universidad Técnica de Manabí, Portoviejo, Ecuador
} 
their research to solve problems related to local development and sustainability, using the native resources of the territory ( solar, hydraulic, wind, biomass, infrastructure and land use, among others).

Given this scenario, the Ecuadorian government strives to adopt solutions to the issue, related to the supply of energy and pointing towards sustainability, where the change of the energy matrix is proposed Rodríguez et al., (2016), that promotes a Diversification of Renewable Energy Sources (FRE), food security and risk reduction.

Viable and equitable growth involves planning strategies associated with three fundamental aspects: social, economic and environmental. In this framework, Ecuador has based its energy planning in compliance with these three areas, guaranteeing the country higher levels of energy sovereignty with a supply of quality energy; Currently it already has instruments such as energy balance, investment catalogs, the new National Energy Agenda 2016-2040, expansion plans in each energy sector, among others (Guayanlema, 2017; Anthony et al., 2017) .

In order to obtain information on the inventories of FRE applications, their potential impacts (environmental, economic, social) and soil vulnerability studies, the proposal is made to plan an information system of a GeoWeb, focused to achieve sustainable development in the Province of Manabí in Ecuador (Saltos et al., 2016), applying the tools of Geographic Information Systems (GIS) and Information and Communications Technologies (ICTs) to perform an inventory of indigenous energy resources and soil infrastructure in the face of seismic risks in the territory, decision making, investment capacity, among others.

As for the evolution of GeoWeb we have:

Web 1.0 was identified with static concepts and little interaction. Web 2.0 appeared as an evolution of the Internet, with great user interaction with the network, being the consumer and the producer of the information. With the arrival of Web 3.0, the Internet will become a semantic network in which the contents will not be searched, but located. The user will not have to go to the data but will be immersed within a three-dimensional screen of information. The GeoWeb can be understood as a large digital (or virtual) globe, in which the information is inserted (Ideca, 2016).

In Ecuador, there are no GeoWebs destined to give sustainability to the territories, understanding this as the expression of the relationship between a spatial position and virtual data of the network (Ideca, 2016). These allow the shared and exhaustive use of maps, data and universal access to GIS applications, together with the increasing availability of geo-referenced content, ease of search and its application to services. The possibility that the transition can generate a new GIS pattern and architecture, highlights open and interoperable services that can be used to support a wide range of geographical applications (Dangermond, 2008; Nehru, 2016), and allow managing the development of territories to a common direction, the sustainability.

GIS is one of the technologies with the greatest worldwide projection due to their contribution to territorial planning, research, teaching, productivity in companies, security, risk prevention, among others (Indriago et al., 2009).

The system will allow the political, administrative authorities, the National Electricity Council (CNE), academic, research entities, teachers, and interested citizens, to have a web computing application, which offers the possibility of providing reliable information and relevant data, in function of making viable the planning of sustainable development in the short, medium and long term, putting Ecuador among the pioneer countries in the field of these applications in Latin America (Rodríguez et al., 2014; Perez et al., 2017).

The province of Manabí is located in the coastal area of Ecuador with a high vulnerability to seismic risks, floods and droughts, and qualifies as one of those with the largest number of homes that do not have electricity, 5\% of the non-electrified population and between $3 \%$ and $5 \%$ who receive poor quality electrical service because they are in areas of difficult access (National Planning Council, 2017); however, it is among the provinces of the country with the highest solar radiation (Rodríguez et al., 2017). In economic management, agriculture, fisheries, and commerce predominate, with a particularly favorable situation from the point of view of the availability of endogenous resources to develop plans to achieve sustainable territories.

The GeoWeb can provide information on the potential of renewable energy sources, offering the possibility of promoting its proper use to achieve the diversification of the energy matrix that, currently, the Ecuadorian government has as one of the strategies of the National Development Plan until 2021 (National Planning Council, 2017); In addition, it will allow students, professionals and administrators to carry out research, execute projects to solve the problem of sustainable development (Vélez et al., 2016; Amerta et al., 2018), to manage the energy use of the province with renewable sources of energy and thereby encourage territories to improve their environmental image.

The information and inventory of renewable sources of energy and natural disaster risks are carried out by different companies and institutions of the state and privately in a manual and dispersed way, and there is no integrated control that provides information in an agile and reliable way for development of the territories and therefore different types of non-standardized reports are handled (Rodríguez et al., 2019; Venkatanarayana, 2016). 
That is why the objective of this research is to design a GIS for information management of Renewable Energy Sources (FRE), which improve its quality, energy efficiency and enhance the diversification of generation sources in the province from Manabí, Ecuador (Saltos et al., 2016; Pérez et al., 2018).

The application is based on the implementation of a tool that facilitates the decision-making process in planning, to achieve sustainable territories in an integrated manner, promoting agile information that provides spatial analysis, determination of appropriate or feasible technology from the point of energy, social, technical-economic and seismic risk view with local resources (Delgado et al., 2017; Gamez et al., 2019).

A GIS of FRE is designed, incorporating a web solution to the model of energy efficiency for the province, so that a simple and affordable method is drawn up in its management by the decision managers, who without being specialists in computer science and with a Basic knowledge of the subject, can manipulate the available tools and access relevant data, making possible the necessary information to carry out the decision-making process in the sustainable energy development of the territories.

\section{Materials and Methods}

This is a documentary investigation, seen as the process carried out that is based on the search, recovery, analysis, and criticism and subsequent interpretation of secondary data (Arias, 2012; Omer, 2017). It is also considered applied because it deals with linking the theory with products, and according to Lozada (2014):

... Aims to generate knowledge with direct and medium-term application in society or in the productive sector. This type of study has a great added value due to the use of knowledge that comes from basic research. In this way, wealth is generated by the diversification and progress of the productive sector. $(2014$, p. 35$)$

Different methods will be used for the collection of cartographic information related to energy and risks, and the Geographic Information System for Sustainable Development (SIGDS), based on a GIS and ICT philosophy, will be proposed, offering possibilities to link the inventory of the facilities and systems that take advantage of the FRE, the management of renewable potentials, the environmental impact and natural risks. All this favors the development of strategic planning models at different scales and levels, with the ability to ensure the integrated use of available resources in a scheme of distributed and sustainable energy use from the local level. The GeoWeb is located on the UTM servers.

To carry out the study, it relied on tools and methods such as the domain model, through which the elements that participate are exposed, as well as the relationship between them. This model allows to represent the most relevant elements that exist or happen in the system environment and is described through UML (Unified Modeling Language) diagrams, which expose the domain classes and their relationships. The domain model is a conceptual model of those issues that relate to a particular problem; According to Garcia, it represents the conceptual classes of the real world and not of the components of a software package.

RUP (Rational Unified Process) business modeling was also used, which proposes the existence of various alternatives that allow the current state of a business to be evaluated (Rumbaugh et al., 2000). According to Pérez, it is a methodology whose objective is to provide order and a structure for software development, having a set of activities that transform users' requirements into a system.

The research procedure developed was the investigation of theoretical references necessary for its scientific approach, selection of tools and infrastructure, design and creation of the database, programming of the portal; subsequently, inclusion of statistical data, integration of the web solution to the energy efficiency model, testing of the portal that includes the verification of the decision-making process in the sustainable energy development of the territory, opening of the portal to the general public.

\section{Results and Discussions}

The map servers are those that will help to translate the solution to the work proposed through the GeoWeb. The most used map servers taking into account usage criteria; they aim to access existing geospatial information, usually on servers in different formats, and serve the information to map clients through standard protocols.

Users make requests from customers who access vector information (graphic and alphanumeric) and / or raster and can generate map images that are served in the form of raster images (PNG, JPEG, GIF, among others), or respond to requests for access to information related to maps served as properties of an element.

Bazurto, J. J. B., Falcones, V. A. M., Gámez, M. R., \& Arvelo, M. G. V. (2019). Geographic information system for manabí sustainable development. International Research Journal of Management, IT and Social Sciences, 6(6), $17-$ 28. https://doi.org/10.21744/irjmis.v6n6.741 
Geometries offer geospatial information in vector format, including alphanumeric geometries and attributes for the customer to process and represent or manage locally. The coverages give geospatial information of different types to the clients, with the particularity of offering the original information without the need for it to be processed. This is useful for accessing data such as digital terrain models, remote sensing information files, among others. The catalog allows access to metadata and searches for information on cartography and geospatial information processing, sending the final results to customers as route calculation, among others.

Two recognized techniques were used for the realization of the domain model and with it the obtaining of the object diagram; the first was carried out by looking for nouns in textual descriptions that reflect that reality or context; the second, proposed by Craig Larman in his book "UML and Patterns" and which was selected to perform this section, which consists of a predetermined table of concepts that are sorted by different categories and help classify the concepts of the domain itself (Larman, 2004). Figure 1 shows the entities that make up the general domain model that was applied.

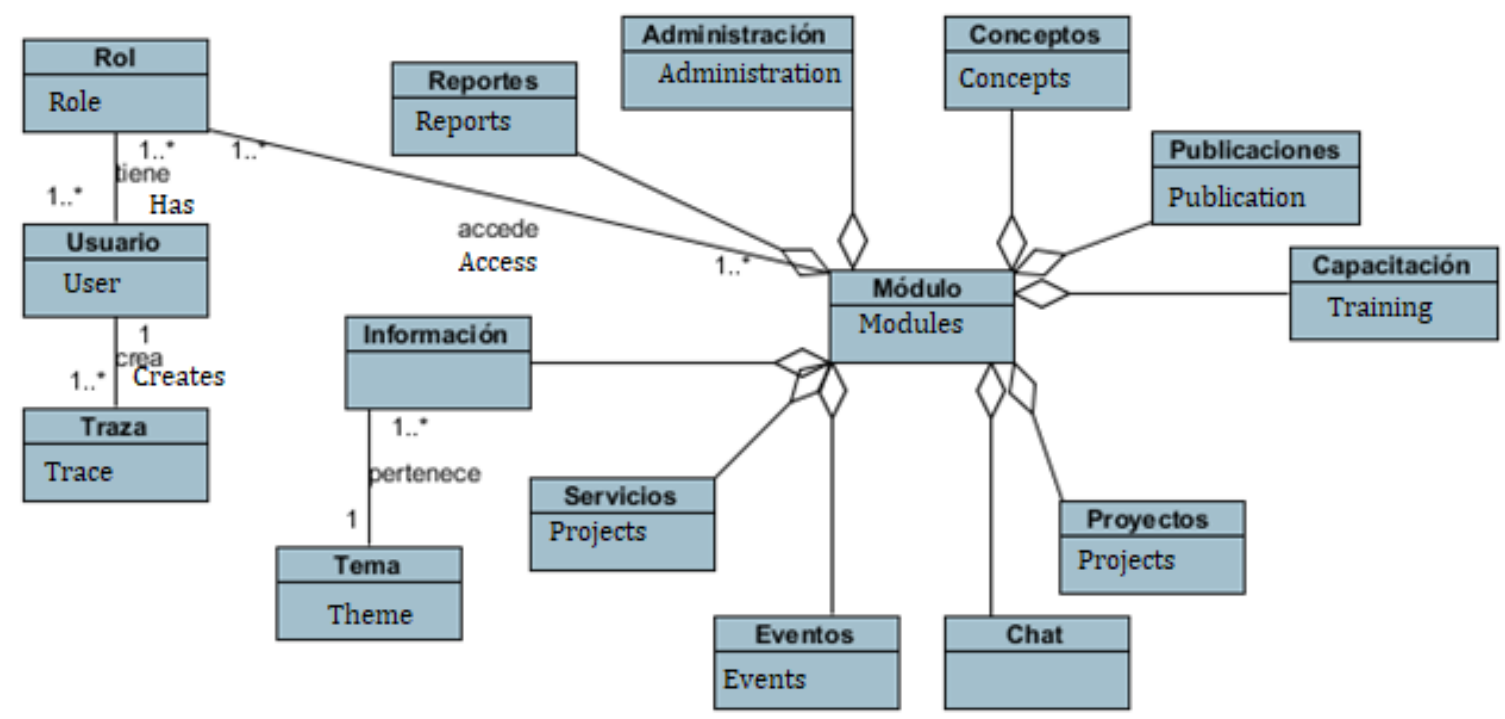

Figure 1. Representation of the domain model in general

In Figure 2, we can see the domain model that is applied in the GeoWeb, where the information update function should only be available to users with the operator role; Users who have privileges to manage information in the GIS can only do so in their municipality of registration, the GIS module must be visible only by those users with prior registration in the application; only the FRE inventory will be managed and not the FRE potentials.

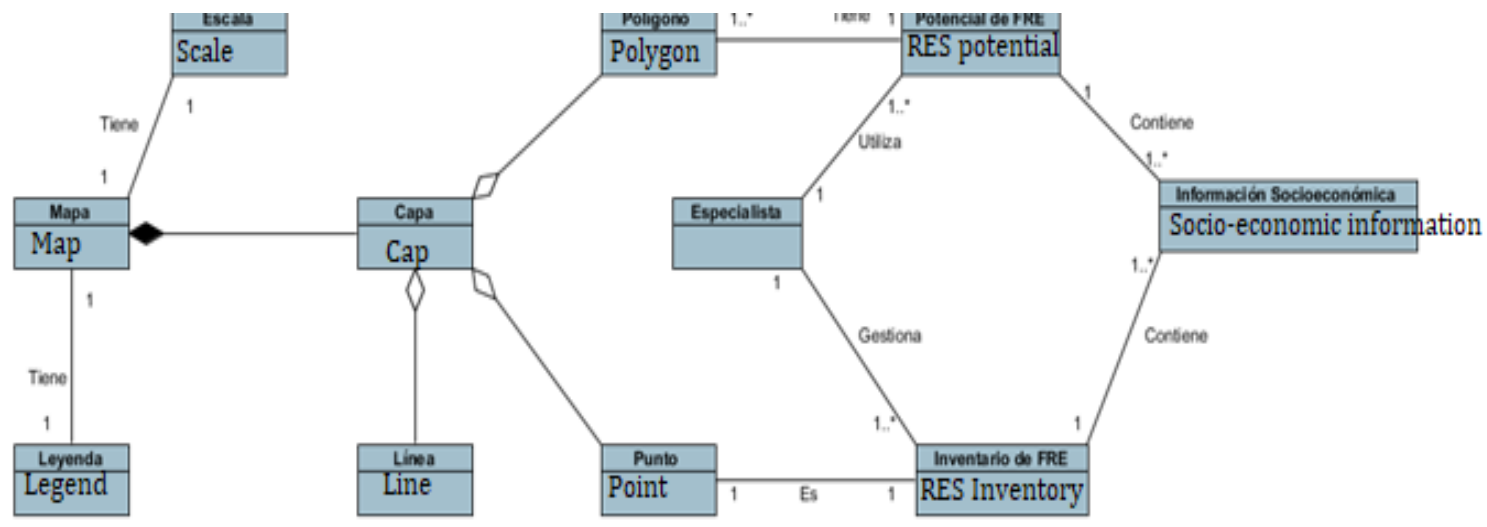

Figure 2. Representation of the domain model 
Architecture and configuration of the GeoWeb application

The SIGDS is integrated by the Geoportal and the GIS; the first provides statistical information shown in tables, graphs, diagrams, and reports; and the second offers the same information but georeferenced in maps, that is, that this computer tool manages to visualize, capture and process the different statistics found in the system in cartography of inventory of renewable and conventional energy resources, the availability of land and the risks of natural disasters; All of this is outlined in the structuring of projects aimed at the sustainable development of the territory through the use of endogenous resources. The structure of the SIGDS is shown in Figure 3.

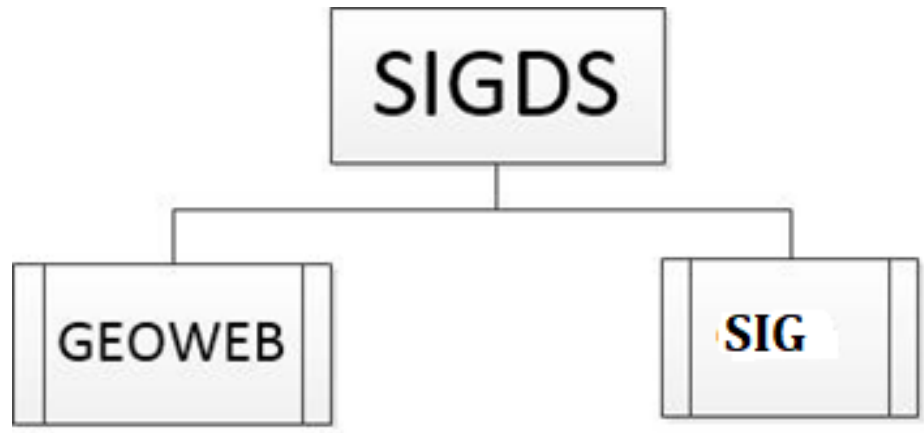

Figure 3. SIGDS structure

Figure 4 shows the graph that describes the computer tools and the process of how users access the information.

\section{GEOWEB}

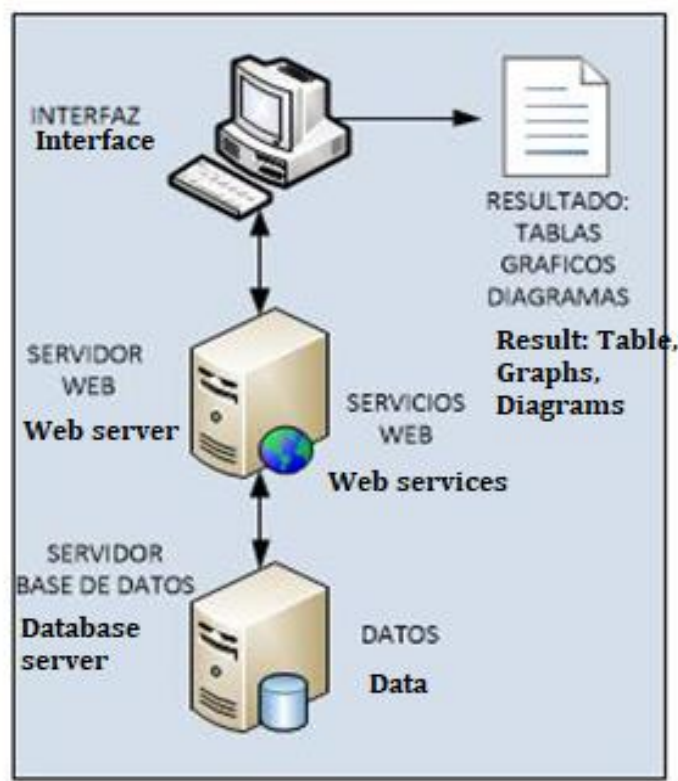

Figure 4. Geoweb architecture

In the interface, through browsers such as Google Chrome, Mozilla Firefox, Internet Explorer, Safari, among others, the user with their respective role chooses between administrator, observer, operator or auditor. For Web Services, Geoserver software has been used as a geographic web service provider that allows you to share and edit geospatial data, or what is the same, as a free alternative to a map server. It has been designed from the beginning to operate under interoperability standards. Publish services based on data sources using open standards. It complies with the Styled

Bazurto, J. J. B., Falcones, V. A. M., Gámez, M. R., \& Arvelo, M. G. V. (2019). Geographic information system for manabí sustainable development. International Research Journal of Management, IT and Social Sciences, 6(6), $17-$ 28. https://doi.org/10.21744/irjmis.v6n6.741 
Layer Descriptor (SLD) specification, which makes it possible for a user style to be applied to a certain layer of the Web Map Service (WMS) (Mas, et al., 2010). Then, it is configured and conditioned by creating the roles and their permissions to the WMS and Web Feature Service (WFS).

In relation to the data, Postgresql is used as a relational database management system oriented to free software objects, which allows the hosting of information considered persistent in the SIGDS; Relational database systems allow them to be managed according to the rules of relational algebra, storing data in tables that contain lines and columns, and that with the use of keys the tables can be related to each other (Denzer, 2002). Since most of the data corresponds to geospatial information, then it must be supported with Postgis software, which provides a server with consistent management of geospatial data (Lamas et al., 2013); this is a module that adds geographic object support to the PostgreSQL object-relational database, making it a spatial database for use in geographic information systems. The same package implements spatial extensions based on the OGC specifications (Open Geospatial Consortium, 2018). For the result, you have the outputs that are the tables, graphs, diagrams, and reports that are generated in the system based on the requirements of the user shown in statistics.

\section{Identification of requirements}

The computer application is aimed at satisfying end-users, based on the model of the domain obtained and from it the different actors and responsibilities, with the aim of guiding development towards obtaining a design that meets expectations of the end-user. Generally, the actors in the system correspond to the workers and / or business actors. From this concept, it was possible to identify the actors of the application that is developed taking into account the role they play in their interaction with it.

In the work the different cases of use of the system are modeled to arrive at the main class diagram, here are most of the developed components (using languages such as JavaScript and PHP); and the second, where there are components that will provide services specifically configured and adapted according to the demands and requirements of the first section. In the first section there is the SIGDS package, where all the gears and particularities that have been designed to achieve the conceived objectives are concentrated, which consists of several sub-packages and main and essential classes that make it possible for the application to work properly optimal; The elements that make up the main package will be briefly explained below.

There is a hierarchical structure that begins with the master class, which has all the possible general elements that will be integrated into the controller object of the application; "Master" is extended by the classes "inventories" and "potential", defining the two main final pages that are the inventory and potential type, adding specific features that will be witnessed only within them, and in turn each is extended by the classes of small final pages of this hierarchy. These final pages enrich the data that is handled in them making each user request answered satisfactorily.

The "master" class inherits from the "TPage" class, which is one of the classes provided by Prado to make a given module behave like a traditional web page; Each module or page created by the use of the "TPage" class has two key elements, the one with a ".page" file name suffix that would be the template file, and the one with a ".php" file name suffix. Which will be the driver file for that page; This framework establishes as a rule that each page has two files, the one that will play the role of a client-side template and the one that will be the server-side controller; the name of the final page would be the same without suffixes that precede it.

Clarifying, Prado is a framework based on various components by the creation of instances, with programming oriented to events caused by users and that are captured in server events to develop applications and make the interaction of the components more viable, associating the methods and functions with events to reduce repeated low level coding (Espinoza, 2012).

An example would be the following:

Template: "sigds_potencial_solar_directa.page"

Controller: "sigds_potencial_solar_directa.php" Page

name: "sigds_potencial_solar_directa"

The elements above are referred to in the diagram shown in Figure 7 with the generic names "Content_FRE .php "and" Content_FRE.page "to avoid explanation in 40 different design diagrams. It aims to show, in just one diagram, the use of most of the technologies in operation within each final page of the application in general.

Within the SIGDS package, there are 3 main sub-packages organized in such a way that in the "Application.protected", you can find all the final pages of inventory and potential type; within the "Application.database" the classes considered non-spatial persistent will remain, and in the "Application.assets" all 
packages containing libraries, scripts and routines will be present, some of which will be called to be used on the server-side and others from the client-side.

It should be noted that the ".page" ending file is a template only for the final page in question, but in the SIGDS the "Layout" class that inherits all the functionalities of the "TTemplateControl" class provided by Prado is used as a general template, which is formatted with the same tags that work in HTML, in addition to other graphic components added by the framework. The general template is based on the concept introduced by Prado developers called "Master and Content", which allows the application to share graphic portions between more than one page, such as the header, footer and menu principal.

The "Layout" will have what will be repeated in all the templates at the page level, leaving a section using the "TContentPlaceHolder" component that will be waiting for the injection of the component also provided by the framework called "TContent" that will be found as a template at the level of final page; This component will be found in the file with the ending ".page" and is the one that will contain all the graphic information that will be displayed on the client-side. For all the final pages, most of the work is done in its template file, that is, in which it has a suffix of the ".page" file name since this section is what allows the client-side programming.

This is where the "GeoExt" packages come in (used to build web applications for maps using a set of libraries in JavaScript (Nieto et al., 2013)), "Ext JS" (component library that provides tools for create good graphics web applications (Fernández et al., 2011)), in addition to "Openlayers" (JQuery library of the JavaScript library that facilitates interaction with HTML documents (Pacheco, 2013)). These three packages provide access to geographic web services provided by the "GeoServer" software through the use of "Ajax" which will provide access to them in the background and asynchronously.

In the second section, there is the Prado Framework and it has been used as a free alternative to a PHP framework, with the aim of making possible the manipulation of each module of the application in a simple way and with the minimum possible errors, since it is a well-defined conceptual and technological support structure, usually with specific artifacts or software modules, on the basis of which, any project can be organized and developed.

The sub-packages used within this package are "System.Web.UI.ActiveControls" (based on the concept of "Active Controls" or active controls that allow the controls provided by the framework to work taking advantage of transactions through AJAX), "System.Data" (based on active registration, better known as "Active record", whose main purpose is to encapsulate access to the database and add domain logic to such data), "System.Security" (which provides security to the application taking advantage of some topics known as "Viewstate Protection", which are prevention policies against the misuse of data that can be used to restore the pages to the last state seen by end-users before making the request in allowed ways ), and "Cross-Site Scripting Prevention" (also known as XSS, which consists of injecting malicious scripts into the page, hiding it's between legitimate requests providing data and user account settings and access to restricted areas).

GeoServer, in addition to the declaration of the "unites" workspace where all the access information to the geographic data that is published by the "PostgreSQL" package accessed by the "GeoTools" sub-package (González \& González, 2013) will be contained, providing access to data of different formats that meet standards to manipulate geographic information, using data structures based on the OGC specifications (Open Geoespatial Consortium, 2018); the services provided by it are accessed by the SIGDS using well-defined functions and algorithms based on the use of the "Geoext" and "Openlayers" sub-packages.

All-access to the package is done through the package contained within "GeoServer" called "spring security" which is a powerful, highly customizable framework for access control and user authentication (Alex et al., 2004).

As for PostgreSQL, it is used as a relational database management system oriented to free software objects, to allow the hosting of information or data that are considered persistent in the SIGDS and how most of this data will be geospatial information, then you must rely on the "Postgis" package, which enables the current package to work with spatial data.

There is also the Ajax package, which provides a technique that allows a server and a web browser to exchange information asynchronously (Firtman, 2011). This technology makes use of the XMLHttpRequest object that is used as an API (Application Programming Interface) that the most well-known and popular web browsing clients have on the web; it can be invoked from JavaScript and other scripting languages included in a web browser, and is used to transfer and manipulate XML data to and from the web browser, establishing a separate connection channel between the client-side of the web page and the server (Working Group Note, 2016). This package is used by the sub-packages "GeoExt", "Ext JS" and "OpenLayers" in addition to the "Framework Prado" package, among others.

Bazurto, J. J. B., Falcones, V. A. M., Gámez, M. R., \& Arvelo, M. G. V. (2019). Geographic information system for manabí sustainable development. International Research Journal of Management, IT and Social Sciences, 6(6), 17 - 
Design

Principles the design principles used for the development of the user interface, the output format of the reports that are issued in the system and the elements are taken into account for the help of the application are described below.

\section{Interfaces}

The design of the interfaces was conceived in 8 sections as shown in figure 5:

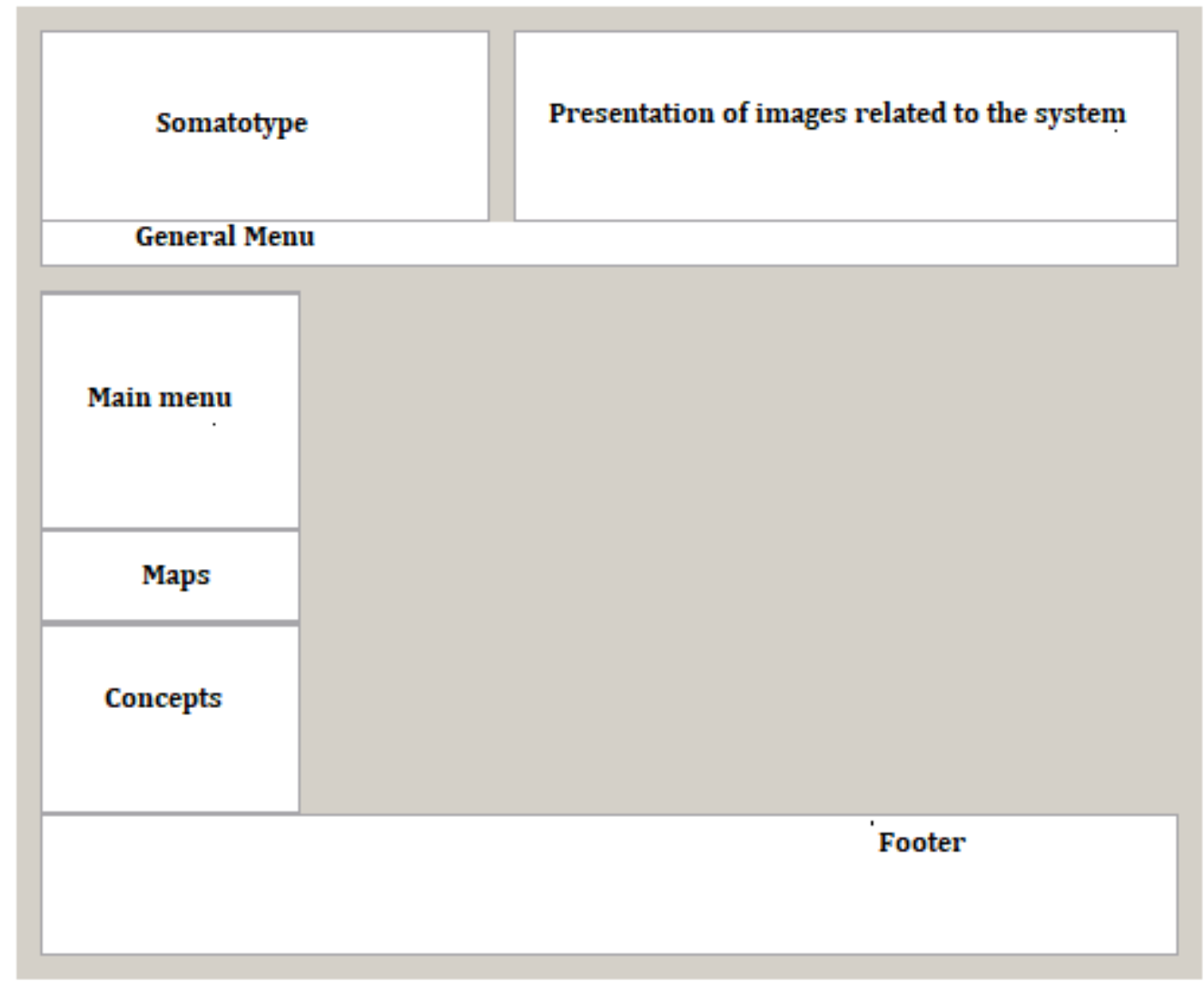

Figure 5: General interface prototype

Each section described in the interface is described below:

Somatotype: logo and name of the application.

Presentation of images: an animated set of illustrations related to FRE.

General menu: general system menu.

Main menu: menu with different options shown to the user depending on the role they have.

Concepts: concepts related to FRE.

Maps: in this section, you can access the part of the system maps.

Footer: shows the basic reference data of the client, that is, the CIPEL.

Information: main section where the information requested by the user is displayed.

The output format of the reports issued

In any application, the way of displaying the reports constitutes an important element for the value to the end-user, so finding the ideal way to present it to users is a key aspect. The application offers the possibility of displaying reports in different ways such as in pdf, in Excel and in bar graphs, depending on the need of the user.

The GeoServer printing module facilitates the hosting of the MapFish printing service in the GeoServer instance. This module is an API for adapted printing that works through HTTP, useful in map applications developed using JavaScript, which is provided by MapFish. To achieve interaction between the print services already installed in 
GeoServer, the MapFish and GeoExt projects provide user interface components to carry out this task, and SIGDS will use the GeoExt option, thus being able to export the main reports as PDF files.

Help

The application incorporates help for all users, allowing actions that could be classified as complex can be performed by a user not graduated from the computer specialty and whose domain is not sufficient to manipulate the main options of the web application.

\section{Error handling}

Security is one of the fundamental points to consider in the implementation of any software, mainly in web applications that must support interaction with a large number of users.

The system uses authenticated user data to identify which role it belongs to; After identifying the role, it makes a request for work permits to the security system of the map server, and it returns a session cookie with which the browser from which said request was made from that moment until it is closed The session enables access permissions on the final pages in question. The security framework used in the process described above is the Spring security framework with the help of Java Database Connectivity (JDBC), which are located in GeoServer and which together allow secure transactions to and from the sources of available data.

In addition, the validation of the client and server-side is implemented, in this way when the system detects an error, the user is informed through messages in red and green (red indicates an error or incorrect action, while the green indicates success in the operation performed).).

Design of the topic base

The physical model of the database was designed, taking into account that it was not necessary to include the logical model because the classes that were identified were persistent and therefore would be part of the physical model.

\section{Deployment diagram}

Different software configurations of the web and database servers were made respectively.

Once you have the Geoweb software configuration, proceed to show how the system is designed and each of its layers; it is observed that the final result is .shp files; A shapefile is a simple, non-topological format that is used to store the geometric location and attribute information of geographic entities. The geographical entities of a shapefile can be represented by points, lines or polygons (areas). The workspace that contains shapefiles includes dBASE tables that store additional attributes that can be linked to the entities of a shapefile (ESRI, 2016), shown in Figure 6.

Bazurto, J. J. B., Falcones, V. A. M., Gámez, M. R., \& Arvelo, M. G. V. (2019). Geographic information system for manabi sustainable development. International Research Journal of Management, IT and Social Sciences, 6(6), $17-$ 


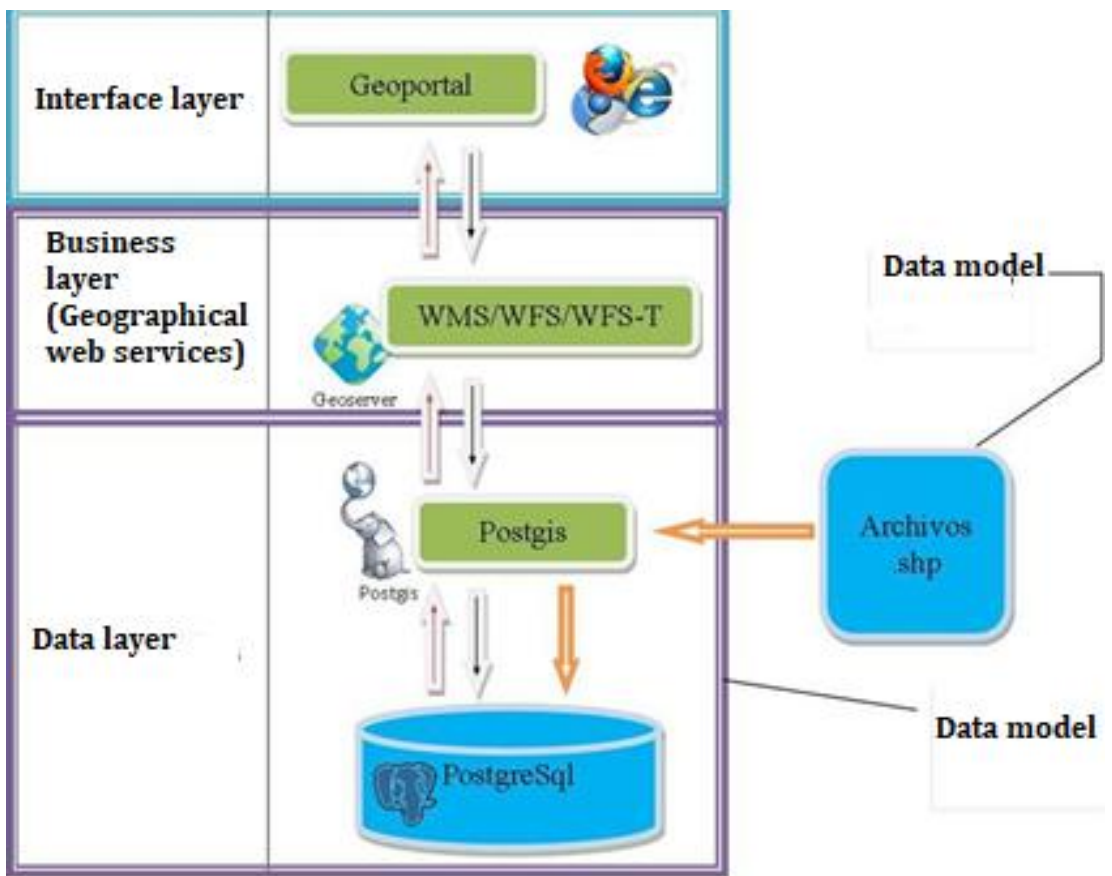

Figure 6: Geoweb layered design

Source: (Rodríguez et al., 2019)

\section{Conclusion}

Although in 2015 Ecuador was ranked fifth in energy security worldwide and fourth in Latin America and the Caribbean in adequately countering the so-called energy trilemma of security, energy equity and environmental sustainability, there is still progress in the matter of territorial sustainability.

That is why, the elaboration of the proposed GeoWeb, propitiates the strategic articulation of a new paradigm of sustainable development that is materialized by introducing the concepts of energy planning and novel considerations for the use of renewable energy sources as a Community social progress alternative.

The creation of geoportals contributes not only to the enhancement of cultural, material and intangible heritage but, through their development, allows access to the geo-referenced geographic information necessary for sustainable development.

The results of the project can contribute to the improvement of the quality of life of isolated communities that do not yet have the electric service, improving the conditions for raising the educational and cultural level of the inhabitants residing in these regions. In the case of the use of networked systems, users participate directly in the generation process by finding the installed systems close to the places of consumption creating awareness of savings and social sustainability.

\section{Conflict of interest statement}

The authors declared that they have no competing interest.

\section{Statement of authorship}

The authors have a responsibility for the conception and design of the study. The authors have approved the final article.

\section{Acknowledgments}

We thank the editor of IRJMIS for their valuable time. 


\section{References}

Alex, B., Taylor, L., Winch, R., \& Hillert, G. (2004). Spring Security Reference. URL https://docs. spring. io/springsecurity/site/docs/current/reference/htmlsingle/.[utoljára megtekintve: 2017. 04. 21.].

Amerta, I. M. S., Sara, I. M., \& Bagiada, K. (2018). Sustainable tourism development. International Research Journal of Management, IT and Social Sciences, 5(2), 248-254.

Anthony, K. A., Oshoke, S., \& Slyvester, O. (2017). Assessment of entrepreneurial education and diversity management: a gateway to sustainable development in Nigeria. International Research Journal of Management, IT and Social Sciences, 4(1), 53-60.

Arauz, W. M. S., Gámez, M. R., Pérez, A. V., \& Fernández, M. C. (2016). Microgrids views from a geographic information system. International research journal of engineering, IT \& scientific research, 2(11), 57-65.

Arias, FG (2012). The research project Introduction to scientific methodology. 6th . Fidias G. Arias Odón.

Council, Y. C., Mayor, L., Vote, R. T., \& Councillors, Y. C. (2017). Your Council. Update.

Dangermond, J. (2008). GIS and the GeoWeb. ArcNews, 30(2), 1-21.

Delgado, G., \& Janeth, M. (2017). Family functionality, protective factors and risk of depression in older adults, region 7 of Ecuador 2016 (Master's thesis).

Denzer, P. C. (1994). U.S. Patent No. 5,307,413. Washington, DC: U.S. Patent and Trademark Office.

Espinoza Aguirre, CB (2012). Comparison of Frameworks for the development of applications with php (Bachelor's thesis, Universidad del Azuay).

Esri, H. E. R. E., \& DeLorme, I. (2016). increment P Corp. GEBCO, USGS, FAO, NPS, NRCAN, GeoBase, IGN, Kadaster NL, Ordnance Survey, Esri Japan, METI, Esri China, swisstopo, MapmyIndia, DeLome NOAA, NGDC.

Fernández, IG, Figueroa, RC, \& Pérez, DF (2011). Architecture proposal of a web tool for the administration of the PostgreSQL manager. Cuban Journal of Computer Science , 5 (1).

Firtman, M. (2013). Programming the Mobile Web: Reaching Users on iPhone, Android, BlackBerry, Windows Phone, and more. " O'Reilly Media, Inc.".

Gamez, M. R., Perez, A. V., Falcones, V. A. M., \& Bazurto, J. J. B. (2019). The geoportal as strategy for sustainable development. International Journal of Physical Sciences and Engineering, 3(1), 10-21. https://doi.org/10.29332/ijpse.v3n1.239

Gamez, MR, Perez, AV, Falcones, VAM, \& Bazurto, JJB (2019). The geoportal as strategy for sustainable development. International Journal of Physical Sciences and Engineering , 3 (1), 1021. https://doi.org/10.29332/ijpse.v3n1.239

González Cortés, V., \& González Cortés, F. (2013). GeoTools integration in gvSIG CE.

Guayanlema, V., Fernández, L., \& Arias, K. (2018). Analysis of energy performance indicators in Ecuador. ENERLAC Energy magazine of Latin America and the Caribbean , 1 (2), 122-139.

Ideca. (2016). Geoweb: La información geográfica relacionada en internet. Bogotá, Colombia: Alcaldía Mayor de Bogotá.

Idriago, J., Cuberos, R., Molina, N., Vanga, M. \& Araujo, C. (octubre de 2009). Los SIG y la educación. Diplomado básico en Tecnologías de Información Geográfica. En M. López, III Jornadas Nacionales de Geomatica. Universidad de los Andes, Mérida, Venezuela.

Lamas, A., Sotelo, F., Sanchiz, MB, \& García, JV (2013). Creation of an OLAP space module for Saiku. University of Girona. Servei de Sistemes d'Informació Geogràfica i Teledetecció .

Larman, C. (2004). Agile and iterative development: a manager's guide. Addison-Wesley Professional.

Lozada, J. (2014). Applied research: Definition, intellectual property and industry. CienciAmérica: Journal of scientific dissemination of the Universidad Tecnológica Indoamérica , 3 (1), 47-50.

Mas, S., García, A., González, A., Rubio, JM, Velasco, A., González, J., \& Ruiz, C. (2010). CartoCiudad: A collaborative commitment of Public Administrations in the field of street vendors. XI Conference on Information Technology for the Modernization of Public Administrations: Zaragoza, Spain , 6-9.

Nehru, R. (2016). Corporate social responsibility \& education for sustainable development. International Research Journal of Engineering, IT \& Scientific Research, 2(3), 72-81.

Nieto, M. A. (2013). Epithelial plasticity: a common theme in embryonic and cancer cells. Science, 342(6159), 1234850.

Omer, A. (2017). Sustainable development and environmentally friendly energy systems. International Journal of Physical Sciences and Engineering, 1(1), 1-39. https://doi.org/10.21744/ijpse.v1i1.2

Open Geospatial Consortium. (2018). Making Location Count. Recuperado de http://www.opengeospatial.org

Bazurto, J. J. B., Falcones, V. A. M., Gámez, M. R., \& Arvelo, M. G. V. (2019). Geographic information system for manabi sustainable development. International Research Journal of Management, IT and Social Sciences, 6(6), $17-$ 
Pacheco Prado, DF (2013). Spatial data infrastructures in smart mobile devices (Master's thesis, Universidad del Azuay).

Pérez, A. V., Gámez, M. R., Briones, V. F. V., Viteri, C. G. V., \& Molina, L. A. V. (2018). Sustainable development seen from environmental training in university linkage. International Journal of Life Sciences, 2(1), 12-20. https://doi.org/10.29332/ijls.v2n1.75

Perez, A. V., Gamez, M. R., Sera, A. S., \& Santos, R. D. (2018). Sustainable energy development: its postulates and principles in the community. International Journal of Social Sciences and Humanities, 2(2), 214-225. https://doi.org/10.29332/ijssh.v2n2.167

Perez, A. V., Gamez, M. R., Viteri, C. G. V., \& Quiroz, A. M. V. (2017). Community power as a driving force for sustainable local development. International Research Journal of Engineering, IT \& Scientific Research, 3(4), 819.

Pérez, AV, Gámez, MR, \& Jurado, WC (2017). AXIS 06-10 Local energy development based on climate change mitigation. Memories University of Azuay, (XVI), 319-327.

Quiroz, A. M. V., Gámez, M. R., Oliva, J. C., Pérez, A. V., \& Mieles, G. M. (2013). Photovoltaic, a Choice, Quality to Electric Service Chone Canton. Development, 12.

Rodríguez, G., Pérez, V., Saltos, A. \& Castillo, J. (2016). Sustainable Transformation of Energy Matrix. International Research Journal of Engineering, IT \& Scientific Research, 2(9), p. 28-33.

Rodríguez, G., Veliz, B., Pérez, V. \& Nieto, H. (2014). Los sistemas de Información Geográfica, Las Técnicas de Informática y las Comunicaciones - Por un desarrollo energético sostenible en América Latina y el Caribe. Rio de Janeiro, Brasil: Geospatial Media and Comunicação Ltda.

Rumbaugh, J., Booch, G., \& Jacobson, I. (2000). The unified modeling language: reference manual . Addison Wesley

Venkatanarayana, I. (2016). Startups in India: sustainable development. International Research Journal of Engineering, IT \& Scientific Research, 2(3), 43-49.

Working Group Note. (2016). XMLHttpRequest. Recuperado de https://www.w3.org/ TR/XMLHttpRequest/. 